\title{
BEYOND THE CALL OF DUTY: REALITIES OF WORK- LIFE BALANCE IN THE UNITED ARAB EMIRATES EDUCATION SECTOR
}

\author{
Olatunji David Adekoya* \\ University of East London \\ Hakeem Adeniyi Ajonbadi \\ Birmingham City University \\ Gideon Iheukwumere Okorie \\ University of Nigeria \\ Ibrahim Olaitan Jimoh \\ Kwara State University
}

\begin{abstract}
Previous research have been intrigued to assess the mechanisms used by employees to cope with tedious work schedules and other areas of their non-work lives. While there are yet to be sufficient studies that explore the countries in the Middle East, this paper aimed to explore the realities of WLB among professionals in the education sector in the United Arab Emirates (UAE). We further considered the implications of workplace and family support, and organisational culture on employees' WLB and productivity. The study employs the use of qualitative data generated from semi-structured interviews of 41 lecturers across seven higher education institutions in Dubai, UAE aimed at investigating the various contexts of WLB.
\end{abstract}

Keywords: Work-life Balance (WLB), Flexibility, Productivity, Lecturers, Organisational Culture, Qualitative, Workplace Support.

Received: 20 August 2019

Accepted: 31 December 2020

https://doi.org/10.33736/ijbs.3166.2021

\section{INTRODUCTION}

The United Arab Emirates is a country located in the South-Eastern part of the Arabian Peninsula and among the six Middle-East countries in the Gulf Cooperation Council, which comprises the energy-rich Gulf monarchies (Sikimic, 2015). The UAE remains an attractive destination for global workforce migration due to unique features such as its law and order towards employment, the falling cost of living, its multi-cultural environment, low taxation policies and tax-free personal income (Abbas, 2018). According to Numbeo (2020), the cost of living in the UAE is $12.48 \%$

* Corresponding author: Royal Docks School of Business and Law, University of East London, United Kingdom; Tel: +447 44864 7131; Email: oadekoya@uel.ac.uk 
lower than in the United States. Despite the numerous benefits offered within the country, it records one of the highest employee turnover and attrition rates in the world (Jabeen, Friesen, \& Ghoudi, 2018). According to Khalife (2016), the global average turnover rate is between 20 to 25 per cent, however, the UAE reports as high as 31 per cent. Al-Masri (2015) evinces that the UAE labour market regulations are only strong and visible on paper but remain ineffective in reality. Hence, with the excess supply of skilled, semi-skilled and unskilled labour from the international market, employers of labour tend to reduce the reward for work, which in turn brings about high employee attrition rates (Jabeen et al., 2018).

The evaluation of the UAE Federal Authority for Government Human Resources (2014) on employee turnover rates finds that the rate is highest among workers in the education sector. According to the report, families in the teaching profession recorded in excess of 400 persons on a quarterly average. While the United Arab Emirates (UAE) through the labour law strives to make the working conditions in the country as favourable as possible both in the private and public sectors, within the last two decades, there have been increased debates pertaining to the importance of balancing work and family obligations (Guest, 2002; Pradhan, 2016). The implications of the imbalance have become a global concern for the entire labour force (Karatepe, 2013). More so, WLB among the college teachers across the middle-east has been sparse (Naithani, 2016). This is due to the limited time devoted to career planning and the absence of perceived organisational support towards career progression (Naithani, 2016).

Work-life balance (WLB) refers to the ability of an employee to combine both work-related and non-work-related responsibilities without any arising conflict between the two domains (Kalliath \& Brough, 2008; Nizam \& Kam, 2018). Work-life conflict (WLC), which is the opposite of WLB, arises from the inability to achieve WLB and generates a myriad of adverse effects on an employee's job performance and health (Naithani, 2016), familial duties and relationships (Greenhaus \& Powell, 2006), and personal interests (Githinji \& Wekesa, 2017). Given the unique socio-cultural, political, and economic factors which vary in several countries, issues pertaining to these factors have been adjudged to influence WLB practices. The influence of organisation culture on WLB stands as one of the primary factors that either promote or impede WLB practices (Rao, 2017). Organisational culture encapsulates the need to work for longer hours to reflect an employee's level of commitment to the organisation or doggedness to achieving work duties; likewise, the level of support received from the organisation displays its culture (Lester, 2015). WLB has also been linked to the need for workplace flexibility, and particularly employee flexibility wherein an employee has the power to choose when, where, and how work is to be done (Githinji \& Wekesa, 2017). However, in many cases, WLB in many professions tend to be unattainable (Naithani, 2016).

In the UAE, 56 per cent of expats claim that their earnings remains the primary motive behind their migration, compared to 22 per cent globally (Naithani, 2016). The UAE is ranked 10th among the most desirable places to work in the HSBC ranking (HSBC Expat Explorer Survey, 2017). Nevertheless, among the foremost reasons for its increasing turnover rate is the nationalisation policy which replaces expats with nationals; this has led the researchers to investigate the reality and sustainability of the improvements in work-life balance among lecturers in the UAE. We, therefore, aim to explore the realities of WLB among the employees within the selected colleges. Through this research, the researchers aim to review the nature of work in the Middle East. More specifically, the study focuses on measuring the importance of work-life balance on the 
productivity of employees and the performance outputs in the higher education institutions (HEIs) in the UAE.

\section{LITERATURE REVIEW}

\subsection{Work-Life Balance and Lecturers}

Work-life balance (WLB) refers to the extent to which an individual's effectiveness and satisfaction in work and family roles are compatible with the individual's life priorities (Greenhaus \& Powell, 2006). Similarly, Kumar and Janakiram (2017) posit that "work-life balance is the individual perception that and non-work activities are compatible and promote growth in an individual's current life priorities." WLB also connotes an individual's satisfaction and proper functioning at work and home, with minimum conflicting roles, otherwise referred to as work-life conflict (WLC). Further asserted was the inclusion of the minimum conflicting roles rather than an absence of it, and this is a major distinguishing factor in their view of the subject (Kalliath \& Brough, 2008; Fapohunda, 2014). WLB has also been implied as an individual's ability to meet their work commitments as well as other non-work and family commitments (Rao, 2017). Hence the predominant themes raised as it pertains to WLB are the obligations or responsibilities of an employee given the two domains, that is, work-related and non-work-related activities.

It is obvious that employees and employers also have a personal life that is outside of their workplace, as such, the need to take care of their families, have breaks or leisure and develop themselves is also paramount (Rao, 2017). Many organisations tend to value the efforts toward increasing productivity and output at the expense of the lives of their employees, hence the need to consider a work-life balance for employees emerged as a global concern (Karatepe, 2013). Divorces and other forms of family separation have become the resultant effect of too busy, too tight schedules for married couples; thus, the notion of work-life balance (WLB) is one that seeks to create an equilibrium, a favourable working and personal life climate, whereby people's jobs do not encroach into their personal and family lives (Nizam \& Kam, 2018). It is, however, necessary to further examine the significance of work-life balance on employees' productivity and the organisation's performance.

There has been an ongoing concern over the years regarding the WLB of academics or lecturers in diverse research contexts (Catano, Francis, Haines, Kirpalani, Shannon, Stringer, and Lozanski, 2010; Husin, Ghazali, Abdullah, \& Bin, 2018). This has led to several arguments among professionals within the educational sector and categorically, the higher education institutions, likewise among policymakers in different countries (Nizam \& Kam, 2018). The need to juggle between their work-related and non-work-related responsibilities have been adjudged to expose lecturers to negative health effects, discrimination, job dissatisfaction, role conflict, and family conflict (Winefield, Boyd, \& Winefield, 2018). Similarly, Coetzee and Rothmann (2005) note that the excessive workload most lecturers often battle with generates high levels of stress and they most times transfer the frustration from the workplace to their homes leading to family crisis and eventually separation for those that are married, while cases of persistent aggression and isolation is found evident in unmarried lecturers. Many of the lecturers have become immersed into their jobs wherein they have turned their jobs into their first love while other responsibilities follow; however, studies (Catano et al., 2010) have revealed that lecturers that pay excessive attention to 
their jobs at the detriment of their non-work-related roles often suffer the effects sooner or later because the imbalance creates a negative effect on their personalities both at work and outside of work. The inability to achieve WLB among lecturers have been attributed to their professional culture, which includes working for longer hours and workplace inflexibility.

\subsubsection{Research Hypothesis}

To effectively and efficiently carry out this research, we present the following hypothesis:

$\mathrm{H}_{1}$ : The work environment does not support WLB practices

$\mathrm{H}_{2}$ : WLB does not have a significant impact on employees' productivity

$\mathrm{H}_{3}$ : Organisational culture related to WLB does not influence organisational performance

\subsection{Theoretical context}

A wide range of theories have been employed by several studies in the efforts to provide a clearer understanding into the concept of WLB in various contexts; however, the predominant theories include the border theory, spillover theory, work-enrichment theory, compensation theory, and integration theory. Based on the need to integrate the major constructs, that is, work-life balance, employee productivity and organisational performance, this study draws some insights from the compensation theory.

The compensation theory describes work-life balance as an attempt of individuals to recompense dissatisfaction in a domain with conscious efforts for satisfaction in another domain (Rao, 2017). Viewing the theory in two directions, that is, reactive and supplemental, Zedeck and Mosier (1990) explained that the occurrence of supplemental compensation exists when individuals make efforts to switch from a negative experience or outcome in a particular domain to a positive one in another domain. The reactive compensation takes the form of an individual's effort to correct the negative experiences in one domain by seeking to engage in the domain with positive experiences; for instance, employees engage in leisure activities outside of the work domain after a tiring experience at work. It comes as a response to ward off stress and depression proceeding from a particular domain, either work or family domain (Kumar \& Janakiram, 2017). Similarly, Pradhan (2016) construes that the theory is premised on the need to make use of resources in providing for the needs of one domain from another domain. Its relevance to this study is to serve as a measurement tool to identify common causes of the work-life imbalance; as such, this theory provides a blueprint for the findings of this study to either accept or negate the assumptions and notions behind the theory in the context of the study.

\section{RESEARCH METHODOLOGY}

This study adopts the qualitative research method and employs the constructivist-interpretative approach, which enables researchers the ability to draw insights from the lived experiences of the study participants (Saunders, Lewis, \& Thornhill, 2016). Adopting this method and approach is deemed fit to provide an in-depth understanding of the research concept and context (Bryman, 2016). In addition, Saunders et al., (2016) aver that the use of the qualitative method helps the research to have a better understanding of the 'why' and 'how' which is less obtainable from the quantitative research method that focuses mainly on the 'what' aspect of research. Also, Howell 
(2013) suggests that the qualitative approach gives the research results a human voice given that it does not depend merely on descriptive components but enables the researcher to obtain detailed observation from the phenomena. Nevertheless, despite the strengths of the qualitative research, it has been criticised to take into account a small sample of the population which may not reflect the situation of a large or entire part of the population for generalisation purposes (Creswell, 2016). The overarching research question aims at uncovering the realities of WLB among the professionals in the UAE education sector (HEIs). Rather than taking a random universal theory on work-life balance, which may be applicable in some regions or countries, the researchers also employed the use of a deductive research approach which seeks to move from theory to findings, that is, the underlying theories serve as a blueprint for which the findings of the research are anchored (Saunders et al., 2016). The deductive approach, therefore, helps the researchers to establish a relationship between the compensation theory and the research findings to ascertain if there are elements within the findings that correlate with the underlying assumptions of the theory.

Therefore, to facilitate the unravelling of complex phenomena enclosed in the research context, particularly in the case of in-depth information gathered on individual cases, the researchers conducted semi-structured interviews to enable enough flexibility regarding the type and amount of information divulged by the respondents, coupled with the openness to deriving new perspectives (Bryman, 2016). In this study, we selected a sample of forty-one (41) lecturers across seven (7) HEIs in Dubai, UAE. The study was limited to the selected participants and HEIs, given the constraints of time to interview a larger part of the population which was challenging as the study participants could only interact for a limited time due to the enormous workload which further evinces the phenomenon explored by this study. The rationale for choosing Dubai is because the Dubai International Academic City hosts a significant number of higher education institutions in the UAE. Also, being the most popular and busiest city in the UAE, it contributes to the insights of WLB. The 41 respondents were evenly distributed across nationals (13) and expats (28), to understand if some of the challenges of work-life balance may stem from the UAE's nationalisation policy. The distribution also further shows that the UAE employs a high number of expats particularly in the HEIs where the UAE records the country with the second largest number of foreign higher education providers (Mackie, 2019). Given the ethical implications surrounding this type of research, the respondents were assured of data confidentiality, as such, the identities of the respondents were concealed as the researchers used pseudonyms as a form of adherence to the anonymity of the respondents. The interviews which lasted between 20 and 45 minutes were conducted in English and recorded using an electronic audio device to ensure that the responses were recorded verbatim.

The research adopted the purposive sampling method, which enables qualitative researchers to deduce a quantifiable and justified amount of knowledge (Saunders et al., 2016). The research also adopted the snowballing approach that allows for existing study participants to recommend other persons that fit the purpose of study (Creswell, 2016). However, the respondents were further selected based on a stratified sampling technique; here, the population was divided into four strata (lecturers, assistant professors, associate professors, and full professors). The division into the identified strata was based on the pilot study, which was foremost conducted to assess the differences between the groups. The HEIs comprised two (2) public and (5) international universities within the Dubai International Academic City. The universities' distribution was deliberate to provide some peculiarities between the public and private universities as it relates to WLB experiences. 
We employed the use of content analysis as suggested by Savall and Zardet (2000) using the thematic data analysis approach that deduces themes from the excerpts of the interviews. Using the coding method, the themes as reported in the research findings were carefully extracted from the interviews to gain insights and understanding of the interpretations from the excerpts. As proposed by Fallery and Rodhain (2007), the transcripts were divided into several sections, and the key sentences were put together for proper analysis after finding the relative patterns. In addition, table 1 presents the framework of the data collection and analysis process, as proposed by Fallery \& Rodhain (2007). The participants, nationals and expatriates alike, were asked to provide comments concerning the following research questions which served as a guiding principle to all the semistructured questions employed in the interview process:

1. How does the work environment support WLB practices?

2. What is the impact of WLB on employees' productivity?

3. How does organisational culture regarding WLB influence organisational performance?

\section{FINDINGS AND DISCUSSION OF RESULTS}

Generally, our findings were based on five themes identified during the data coding process and as reflected in table 1. The emerging themes include long working hours and heavy workload, work stress, work environment, workplace and family support, and workplace culture.

\subsection{Long Working Hours and Heavy Workload}

The opinions of respondents were sought to understand their view of the work environment and to ascertain if it supports a favourable work-life balance for employees. A whopping number of respondents (86 per cent) reported that they are faced with long working hours. They allude that their working hours include both their teaching and administrative responsibilities. Many of the respondents also claim that the heavier the workload, the longer the working hours they face to ensure that uncompleted work is not brought forward to the next day or week. A significant number of respondents work between 10 and 12 hours per day and longer hours during the days fixed for evening lessons. Among the responses recorded were:

"The work environment here, on paper, has some policies that seem to support work-life balance. But in reality, it does not appear so[...]For example, our supposed working hours are 35 hours per week, but you realise that many of the staff members who resume work at about 9 am will have classes till about 6 or 8 pm" (Assistant Professor, HEI - A).

Majority of the respondents confirmed the existence of long working hours in their HEIs. According to Karatepe (2013), an increasing workload reduces the rate of productivity or output of employees. Karatepe (2013) further explains that emotional exhaustion through workload functions as a primary predictor of work-family conflict. This is because a heavy workload which could result in spending more time at work and less time with the family often engenders in family crisis. In many cases, the effect of work stress could spill-over to the family life of the individual further resulting in crisis as a result of the interference of work into family life or vice versa (Husin et al., 2018). 
However, some of the respondents claimed that the heavy workload, although reduces their level of activities at home, however, they often attempt to focus on the positives that the home gives them to cope with the work intensity. Another respondent commented:

"One thing is common and characterises all the levels - the workloads never seem to decrease. They follow you everywhere you go. The only joy is that I try as much as possible to take the positives from my little time I spend with my family and I consider it my motivation to continue working" (Associate Professor, HEI - C).

Generally, our findings show rising concern about the difference between reality and theory regarding the implementation and utilisation of WLB practices. The organisations have in their policies, rules and regulations, 7 hours work per day, which totals 35 hours of work for five days. This vast difference also includes the overall workload on the employees, which demoralises them and reduces motivation for action. The work environment does not seem to support WLB as lecturers are beginning to find the working hours and workload outrageous given that professionals in this sector often go beyond the call of duty.

The findings reveal that 70 per cent of the male respondents spent most of their day at work. They believe that it is a culture within the HEIs to work for longer hours than required or desired, however, with so much to do, there is little or no time to achieve them. Similar reports were evidenced in the studies of Husin et al., (2018) and Lester (2015) where the enormous amount of workload was deemed to be elusive and detrimental to achieving WLB. Also, given that our findings showed that a vast number of male respondents spend the bulk of their day at work, this translates into a drastic reduction in the time devoted to their families and for personal interests which have led to work-life conflict and work-family conflict. This result is also reflected in the study conducted by Winefield, Boyd and Winefield (2018). Results also revealed that half the number of married women were in similar condition as they have hectic workdays and insufficient resting time. Further enquiries revealed that most married women in this category have kids above 20 years old. However, despite the overall work productivity dwindling in their respective opinions, half of the respondents believed that there is self-improvement resulting from these workloads. This evinces some positive effects given that, although, the workload is enormous, there are also gaps that are filled regarding career progressions such as time included in research and community services. Consequently, despite the unequal impacts (positive and negative) from work overload, some employees find a few benefits from working longer hours and work overload. Moreso, our findings reveal that the compensation theory is significant and valid, as some of the participants were able to cope better based on family motivation; hence, they depending on deriving more satisfaction from their homes as a mechanism to cope with work issues.

Table 1: Emerging Themes with Illustrative Extracts

\begin{tabular}{ll}
\hline \hline \multicolumn{1}{c}{ Themes } & \multicolumn{1}{c}{ Illustrative Extracts } \\
\hline $\begin{array}{l}\text { Long working hours and heavy } \\
\text { workload }\end{array}$ & $\begin{array}{l}{[\ldots], \text { my role as the departmental head has increased the hours of }} \\
\text { work because the administrative part of my work is enormous. You } \\
\text { have students and colleagues knocking on your door from time to } \\
\text { time and meetings almost every day. [...], my contract states that I } \\
\text { would be working for only } 8 \text { hours per day, but since assuming the }\end{array}$
\end{tabular}


role, I have worked no less than 12 hours [...] (Associate Professor, HEI - A)

Work stress

Work environment

Workplace and family support

Workplace culture
The stress is just too much [...]. As an academician, I have four roles which include teaching, administration, research and community service; they all consume my time and results in enormous stress which is very unhealthy (Assistant Professor, HEI - C)

As for me, my work environment does not support WLB because of the level of job insecurity in this part of the world and as an expat [...]. Although the pay is good, but if things do not change soon, I may have to return to my home country (Full Professor, HEI - D) The family support that I receive is the main drive for continuing in my present role [...]. My husband and children have been supportive of my work, although sometimes there are issues with coming home late or stressed [...] (Lecturer, HEI - F).

I believe the work culture is a major determinant of WLB. [...], the lack of flexible working options puts us at the risk of crisis both at work and at home $[\ldots]$ (Lecturer, HEI - E)

Source: Researchers' Field Survey (2020)

\subsection{Work Stress}

The respondents were asked about their individual opinions on the influence of a favourable worklife balance on their productivity at work. A significant number ( 92.3 per cent) voiced that they are only able to cope with the heavy workload because of their passion for teaching which is their primary motivation, followed by the high pay or salary and readily available teaching resources. They allude that they undergo high levels of stress, which alters any form of work flexibility to ease the work pressure. One of the participant commented:

"Sometimes I come to work tired because I left the college at about 10 or $11 \mathrm{pm}$ and I have a class to teach the next morning. The stress is much, and it is killing. No matter how productive you are as a person, you cannot go on like that for too long. [...] so, the effect of work-life balance on productivity is tremendous[...] as far as we are concerned here, almost everybody is working under stress" (Assistant Professor, HEI - B).

The responses from the study participants are all-encompassing as they agree that the benefits of flexibility at work would be invaluable. For those with additional administrative responsibilities, their performances are weakened persistently and have negative health implications emanating from increased stress levels. Corroborating with our findings, Naithani (2016) also finds that academicians in the GCC region (including the UAE) are exposed to excessive work stress which has adverse effects on their health. However, from anecdotal evidence, we find that the spill-over theory is dominant in under this theme. Our data evince that many of the participants claim to have experienced a spread in work stress while at home. Although such stress levels were managed moderately, however, there were some cases of WLC due to the reduced participation at home which increased the stress levels of other family members. For instance, a participant commented:

"The stress at work is sometimes unpalatable [...]. My doctor has recommended that I reduce my workload and take more rest. [...] I am already contemplating an early retirement if my institution does not consider reducing my workload and offering more flexibility, because my health is more important at this point" (Full Professor, HEI - G). 
This finds further suggest that work stress is a primary predictor of WLC as it impedes the achievement of WLB. Our findings corroborate with the study of Kirk and Napier (2008), where the stress levels among professionals in the UAE education sector were found as a significant impediment for increased turnover rate. Likewise, many other studies in the western region connote that there is a significant negative relationship between work stress and WLB (Johari, Tan, \& Zulkarnain, 2018; Ren \& Caudle, 2020).

\subsection{Work Environment}

Several studies maintain that the work environment influences employees productivity and wellbeing (Khan \& Sajidkirmani, 2018; Bataineh, 2019). According to Wong, Bandar, and Saili (2017), workplace factors are crucial determinants of WLB for employees because employees are better productive in an environment that is perceived to be conducive for physical, mental and emotional stability. More so, the responses from this study reveal the influence of the work environment on a favourable and flexible work-life balance. Some of the respondents mentioned:

"The work environment is as important as the home environment. [...] I feel safe when I know that I can do my work without any significant concerns about job security. However being an expatriate, the job security is sometimes threatened because the laws of the country give a huge preferential treatment to the citizenry even when they work less [...]" (Full Professor, HEI - F).

"Without a doubt, the UAE is one of the safest countries because of their investment in security, however, sometimes you get frustrated with the way the Emiratis working with you treat you [...] sometimes they cannot be bothered to attend crucial meetings, and that speaks volume of the disparities and unfair treatment in the public colleges" (Lecturer, HEI - D).

Our findings suggest that to achieve a better work-life balance, a conducive working environment is necessary given that many individuals often operate at their optimal capacity in an environment that is calm and supportive. Our research finds that 38.6 per cent of the female respondents and 67.4 percent males claim that their work environment helps them to manage their work-life and personal life. This implies that most females who work in the HEIs face challenges of balancing work and life. This is also the case, as reported in the study conducted by Santos and Van Phu (2019), where it was reported that most women have to combine the office demands and home demands, which often proved difficult and the unconducive work environment escalates the adverse effects. A majority of the study participants that were expatriates equally agree to the presence of unfair treatment relative to their counterparts that are Emiratis. Naithani (2016) reports that the UAE laws enforce the employer to priortise the Emiratis in employment and accord full work benefits irrespective of the type of organisation (public or private).

\subsection{Workplace and Family Support}

The respondents were asked about their experiences as it pertains to the support received from the workplace and family members. While 82 per cent of them implied that they enjoyed more support from their family members (spouses in particular), only 31 per cent claimed that they were supported by their colleagues, line managers and top management. We observed from the responses given that lecturers tend to get more support at home relative to the support received at work. The lack of adequate support in the workplace seems to affect lecturers as they are left with 
no other choice than to devise mechanisms to cope with their work and family roles. The following presents some of their responses:

"I hardly get support from my colleagues at work [...], I cannot blame them because we all have a huge workload. My wife is always supportive, however, it sometimes gets to a point when the work becomes too hectic, and I am unable to fulfil my responsibilities as I ought to, which sometimes brings disagreement between us. I think I find more support at home than at work" (Associate Professor, HEI - B).

"Like I mentioned earlier, my family is the main reason why I am still here [...]. I enjoy a lot of support from my spouse because she often works from home, so it is easy for me to combine work and family. [...] sometimes I feel that I am taking my wife for granted and she and the kids even though they are grown up, but they need more of my presence" (Full Professor, HEI - E).

To further bolster the issues previously raised, the researchers explored the workplace and family support they received. The study revealed that 72 per cent of married males enjoy support from their spouse with regards to family demands and childcare. Adversely, a lesser number of women in the same category (married) enjoyed similar support. An enquiry to discover the discrepancy between responses to this question revealed that patriarchy constituted a large part of the difference where the male population are deemed to hold more power and dominant in the society than their female counterparts. As such, the female employees were saddled with a tri-functional role inclusive of taking care of the home chores, childcare and their professional career.

The study also revealed that dual-earner couples found it more challenging to achieve WLB, which in a few cases resulted in family crisis and separation. These findings are similar to the findings of Munn and Chaudhuri (2015) and Adisa, Abdulraheem, and Isiaka (2019) as it was reported that many of the efforts to achieve WLB by women proved futile mainly because of the frustrations elicited from patriarchal existence, while gender role dynamics led to WLC for dual-earner couples. More so, our findings also revealed that workplace support was minimal for lecturers, particularly among co-lecturers. It was evidenced that the high amounts of workload led to the individualistic approach witnessed among the lecturers as they were unable to set aside their enormous workload to help other lecturers on several occasions. However, organisational support from the management and heads of departments seemed to have improved recently, though it was deemed to be below the desired expectations of the lecturers. This was also the case in the findings of Bozeman and Gaughan (2011) and Husin et al., (2018).

From this instance, the compensation theory is more pronounced and evident, given that the participants rather than rely on organisational support, they sought more support from the home. Therefore, they were able to switch from a negative experience in their work domain to a positive one in their family domain, which supports the supplemental assumption of the theory (Zedeck \& Mosier, 1990). More so, the reactive axiom was evident due to the attempts to correct the negative experiences at work by seeking more time and support from the family.

\subsection{Workplace Culture}

To examine the impact of work culture on organisational performance and WLB, the respondents were beckoned to give comments on the degree to which the prevalent work-life culture in their 
organisations affects their performance at work and at home. An overwhelming percentage $(90$ per cent) ascertained that there is a significant relationship between employees' productivity and organisation performance and familial role performance. From the responses, we observed that the work-life balance culture of the colleges seems to be in contention with organisational performance, and the colleges are also feeling the impact of reduced employee productivity on its performance. The following evince some of the responses:

"This is hard to measure in the sense that, as it were, you find out that the college is trying hard to change its working culture to incorporate and ensure people have a work-life balance[...] as the workload increases, the stress levels increase, and our productivity rate reduces" (Assistant Professor, HEI - A).

"The work culture in my institution is fairly good [...], although sometimes it can be challenging, but I think recently the top management has been trying to effect some changes to the working time and workload" (Lecturer, HEI - G).

An enquiry into the obtainable culture within the HEIs revealed that 80 per cent of respondents affirm that their colleges had existing laws that govern working conditions and culture. Thus, the colleges are not without the polices to regulate the working hours; however, it remains on paper for the records while in practice, it is far from being achieved. Eaton, Osgood, Cigrand, and Dunbar (2015) and Lester (2015) found this to be true in their various studies and context. The respondents also notified that they believed discrimination and bias exist in the treatments from the college to expats and citizens. Up to 65 per cent perceived this to be true. Again, 68 per cent of respondents believed the work environment discourages women from full participation at work. The patriarchal structures seemed to have formed a workplace culture in some of the HEIs; this was also revealed in the study conducted by Cannella and Perez (2012) and Naithani (2016).

Probing into the reasons for the less comfortability of females working in the UAE, Pennington (2017) remarked that women outnumber men in the student population in the UAE. He mentioned that 62 per cent of the students in UAE's federal universities as of 2016 were women, and this also translates to the staff demography. As Pennington noted, it is another phase of the challenge to enrol and retain male students and faculty because they mostly want to go abroad while the women instead prefer to stay in the country. As a result, the 68 per cent from our study that claims gender disparity perceive that the few available men are dominant over the women, and this spreads discouragement.

\section{CONCLUSION}

It has become a global concern and a matter for urgent attention, that host organisations need to consider the working conditions of employees. It is essential to take cognisance of the health risks and hazards associated with induced overtime work, long working hours and the increasing workloads on employees. As many organisations have become unaccountable to their employees, it makes their lives worse off than it was when they resumed working. Hence this study aimed at examining the realities of balancing work life with personal/family life for lecturers working in the higher education institutions in the UAE. The research questions consist of key areas of interest, in the quest to explore the realities of work-life balance of employees in education sector. First, we 
inquired to determine the level of WLB among lecturers in the selected region. However, evidence from this study has shown that there is a significant amount of people who believe that there is a problem with work-life balance in the higher education institutions, and it needs to be addressed. Long working hours being a primary predictor of work-life imbalance engendered several adverse effects on familial responsibilities as the employees claimed to have worked beyond the call of duty. Secondly, given the level of work-life conflict within the study context, the degree of influence on employees' productivity is often negative. Productivity levels are bound to decline in the face of hectic work hours and disequilibrium between work and personal life. However, this does not override the fact that there are exceptions. Although too many workloads and rigid work hours cripple productivity levels among some employees, it does not undermine the truth that individual employees are at their very best under occasional pressures. Also, regarding the workplace environment, the level of support received is incommensurate to the level of work done. Lecturers clamour for more flexibility to also allow them to balance their family lives. Familial supports are higher than workplace support, whereas the reverse should be the case since employees spend more time at work than at home. Finally, in terms of the effect of culture on WLB, our findings revealed that longer working hours, minimal workplace support, and required physical presence at work form the workplace culture and to a significant effect acts negatively on the health, productivity and family and personal life of the lecturers.

More so, the study focused on a theoretical context (compensation theory) of work-life balance to evaluate the case of HEIs in the UAE. The theory explains that individuals who face dissatisfaction in a particular domain, usually tend to gratify and fill up that gap by longing for satisfaction from a different domain. As a result, the domain that provides satisfaction tends to own more of their time and pleasures. This study found this theory in practice, though narrowly, amidst the interview analysis. It found that in some instances, individuals who feel that the spill-overs from work have reduced the attention they give to family, have eventually chosen the work domain as the domain that offers satisfaction and home dissatisfaction. Also, certain individuals would define their perceptions of work and life as one that would allow for more holidays and breaks at the expense of some percentages of their salaries. This states clearly that their most preferred domain is family, and work is a dissatisfaction; hence support the assumptions put forward by the compensation theory.

\section{RECOMMENDATIONS, LIMITATIONS AND FUTURE RESEARCH}

Following the findings from this report, the researchers present some recommendations to enable policy formulation and decision-making, as well as provide insights for further research. Evidence from the research has shown that there is a considerable degree of bias in the administration of UAE labour laws and policies. The high turnover rates found by Khalife (2016) and Al-Masri (2015) are revealed in this research to be skewed towards international workers more than the UAE nationals. Thus, it equally aligns with the report of the Federal Authority for Government Human Resources (2014) where the most employee turnovers were found in the teaching profession.

For policy makers, this study recommends a practical application of items stipulated in the UAE labour laws which upholds job security and working conditions in the UAE for both nationals and expatriates. Whereas the UAE has lofty ambitions attached to its growth and development plan, it is pertinent to understand that the plan will largely involve more expats than Emiratis to come to 
fruition since foreigners comprise about 90 per cent of the UAE's population (World Population Review, 2020). Hence, a better policy execution imperative towards institutions of learning as well as other private and foreign-dominated organisations to ensure fairness in the demand and supply of labour.

The study also has some implications for human resource management (HRM) regarding the facilitation of WLB policies for talent attraction and retention purposes. It is, therefore, important for HRM to rethinking the policies within the organisations in consonance to the future of work particularly in the UAE.

For researchers, we recommend that for further studies, a comparative analysis can be done on a case-by-case basis for UAE nationals and expats to undercover the intrinsic differences in the nature of their work. Why are nationals having more work satisfaction than the foreign workers? What is the size of the gap or difference between both, and the state of it (widening or closing)? What more could be done to curtail the situation? How does the UAE nationalisation policy affect the work-life balance of expats? And many more situations to be considered. Based on time constraint and funding for wider reach, the researchers faced limitations to fully explore the study.

\section{REFERENCES}

Abbas, W. (2018, July 2). Dubai and UAE remain attractive destinations for global workforce. Khaleej Times. Retrieved from https://www.khaleejtimes.com/business/local/dubai-anduae-remain-attractive-destinations-for-global-workforce-

Adisa, T. A., Abdulraheem, I., \& Isiaka, S. B. (2019). Patriarchal hegemony: Investigating the impact of patriarchy on women's work-life balance. Gender in Management, 34(1), 19-33. doi: 10.1108/GM-07-2018-0095

Al-Masri, S. (2015, September 28). Stats and Remedies For Employee Turnover In The Middle East. Entrepreneur Middle East. Retrieved from https://www.entrepreneur.com /article/251091

Bataineh, K. A. (2019). Impact of work-life balance, happiness at work, on employee performance. International Business Research, 12(2), 99-112.

Bozeman, B., \& Gaughan, M. (2011). Job satisfaction among university faculty: Individual, work, and institutional determinants. Journal of Higher Education, 82, 154-186.

Bryman, A. (2016). Social research methods (5 ${ }^{\text {th }}$ ed.). London: Oxford University Press.

Cannella, G. S., \& Perez, M. S. (2012). Emboldened patriarchy in higher education: Feminist readings of capitalism, violence, and power. Cultural Studies, Critical Methodologies, 12(4), 279-286.

Catano, V. M., Francis, L., Haines, T., Kirpalani, H., Shannon., H., Stringer, B., \& Lozanski, L. (2010). Occupational stress in Canadian universities: A national survey. International Journal of Stress Management, 17, 232-258.

Coetzee, S.E. \& Rothmann, S. (2005). Occupational stress, organisational commitment and illhealth of employees at a higher education institution in South Africa. South African Journal of Industrial Psychology, 31, 47-54.

Creswell, J. W. (2016). Research design: qualitative, quantitative, and mixed methods approaches. Thousand Oaks, California: SAGE Publications. 
Eaton, C. K., Osgood, A. K., Cigrand, D. L., \& Dunbar, A. L. (2015). Faculty perception of support to do their job well. Insight: A Journal of Scholarly Teaching, 10, 35-42.

Fallery, B. \& Rodhain, F. (2007). Four approaches for the analysis of textual data: Lexical, linguistic, cognitive and thematic. Retrieved from https://hal.archives-ouvertes.fr/hal00821448

Fapohunda, T. M. (2014). An exploration of the effects of work-life balance on productivity. Journal of Human Resources Management and Labor Studies, 2(2), 71-89.

Federal Authority for Government Human Resources (2014). Overview and analysis of employee turnover in the UAE federal entities (subject to HR Law). Retrieved April 27, 2020, from https://www.fahr.gov.ae/Portal/Userfiles/Assets/Documents/42f53175.pdf

Githinji, F., \& Wekesa, S. (2017). The influence of social environment on employees' work-life balance in the insurance industry. IOSR Journal of Humanities and Social Science, 225, 1520.

Greenhaus, J. H., \& Powell, G. N. (2006). When work and family are allies: A theory of workfamily enrichment. The Academy of Man Marital Statement Review, 31(1), 72-92.

Guest, D. (2002). Perspectives on the study of work-life balance. Social Science Information, 41(2), 255-279.

Howell, K. E. (2013). An introduction to the philosophy of methodology. London: Sage.

HSBC Expat Explorer Survey (2017). HSBC Global Report. Retrieved from http://expat.hsbc.com

Husin, N. A., Ghazali, A. S. M., Abdullah, N., \& Bin Abdul Hadi, M. I. (2018). Work-life balance of Malaysian lecturers. Australian Academy of Business and Economics Review, 4(1), 4349.

Jabeen, F., Friesen, H. L., \& Ghoudi, K. (2018). Quality of work life of Emirati women and its influence on job satisfaction and turnover intention: Evidence from the UAE. Journal of Organizational Change Management, 31(2), 352-370.

Johari, J., Tan, F. Y., \& Zulkarnain, T. Z. (2018). Autonomy, workload, work-life balance and job performance among teachers. International Journal of Educational Management, 32(1), 107-120. doi: 10.1108/IJEM-10-2016-0226

Kalliath, T., \& Brough, P. (2008). Work-life balance: A review of the meaning of the balance construct. Journal of Management \& Organization, 14(3), 323-327. doi: 14.10.5172/jmo.837.14.3.323.

Karatepe, O. (2013). The effects of work overload and work-family conflict on job embeddedness and job performance: The mediation of emotional exhaustion. International Journal of Contemporary Hospitality Management, 25(4), 614-634. doi:10.1108/09596111311322952

Khalife, C. (2016). Revolving Doors: An Analysis Of The UAE's High Staff Turnover Rate. Retrieved from https://www.entrepreneur.com/article/274827

Khan, O. F., \& Sajidkirmani, M. (2018). Impact of work environment on work-life interface of women employees. International Journal of Linguistics and Literature, 7(4), 47-58.

Kirk, D., \& Napier, D. (2008). The transformation of higher education in the UAE: Issues, implications and intercultural dimensions. In, J. Zajda, H. Daun, and L. J. Saha. (Eds.) Nation-building, identity and citizenship education: Cross cultural perspectives (pp. 131142). Springer.

Kumar, V., \& Janakiram, B. (2017). Theories of work life balance - a conceptual review. International Research Journal of Management and Commerce, 4(9), 184-192.

Lester, J. (2015). Cultures of work-life balance in higher education: A case of fragmentation. Journal of Diversity in Higher Education, 8(3), 139-156. 
Mackie, C. (2019, June 13). International branch campuses part two: China and the United Arab Emirates. WENR. Retrieved from https://wenr.wes.org/2019/06/international-branchcampuses-part-two-china-and-the-united-arab-emirates

Munn, S. L., \& Chaudhuri, S. (2015). Work-life balance: A cross-cultural review of dual-earner couples in India and the United States. Advances in Developing Human Resources, 18(1), $1-15$.

Naithani, P. (2016). Impact of health and recreation on work-life balance: A case study of expatriates. International Journal of Social Science and Business, 1(1), 33-45.

Nizam, I., \& Kam, C. (2018). The determinants of work-life balance in the event industry of Malaysia. International Journal of Management, Accounting and Economics, 5(3), 141168.

Numbeo (2020). Cost of living comparison between United Arab Emirates and United States. Retrieved from https://www.numbeo.com/cost-of-living/compare_countries_result.jsp? country $1=$ United + Arab + Emirates \& country2=United + States

Pennington, R. (2017, August 26). Women continue to dominate UAE federal colleges and universities. The National. Retrieved from https://www.google.com/amp/s/amp.the national.ae/uae/women-continue-to-dominate-uae-federal-colleges-and-universities1.622982

Pradhan, G. (2016). Conceptualising work-life balance. Working Paper No. 368. The Institute for Social and Economic Change, Bangalore.

Rao, I. (2017). Work-life balance for sustainable human development: Cultural intelligence as enabler. Journal of Human Behavior in the Social Environment, 27(7), 706-713.

Ren, X., \& Caudle, D. J. (2020). Balancing academia and family life: The gendered strains and struggles between the UK and China compared. Gender in Management, 35(2), 141-165. doi:10.1108/GM-06-2019-0093

Santos, G., \& Van Phu, S. D. (2019). Gender and academic rank in the UK. Sustainability, 11(11), 3171. doi: 10.3390/su1111313171

Saunders, M., Lewis, P., \& Thornhill, A. (2016). Research methods for business students. Harlow: Pearson Education Limited.

Savall, H., \& Zardet, V. (2000). The contribution of the economy to HRM. Personnel, 415, 10-22.

Sikimic, S. (2015, February 12). Profile: What is the GCC? Middle East Eye. Retrieved from https://www.middleeasteye.net/news/profile-what-gcc

Winefield, H., Boyd, C., \& Winefield, A. H. (2018). Work-family conflict and well-being in university employees. The Journal of Psychology: Interdisciplinary and Applied, 148(6), 683-697.

Wong, P., Bandar, N. F. A., \& Saili, J. (2017). Workplace factors and work-life balance among employees in selected services sector. International Journal of Business and Society, 18(4), 677-684.

World Population Review (2020). United Arab Emirates population 2020. Retrieved from https://worldpopulationreview.com/countries/united-arab-emirates-population/

Zedeck, S., \& Mosier, K. (1990). Work in the family and employing organization. American Psychologist, 45, 240-251. 